\section{The quantitative link of lung clearance index to bronchial segments affected by bronchiectasis}

\section{ABSTRACT} lung clearance index ( $\mathrm{LCl}$ ) derived from the multiple breath washout relates to both acinar and conductive ventilation heterogeneity. The latter component predicts an association between $\mathrm{LCl}$ and the number of bronchial segments affected by bronchiectasis. Here, we experimentally demonstrated this association in patients with $C F$, and also examined an ancillary group of patients with non-CF bronchiectasis. We conclude that lung disease severity in terms of number of bronchial segments results in an associated $\mathrm{LCl}$ increase, likely constituting a portion of $\mathrm{LCl}$ that cannot be reversed by treatment in patients with $\mathrm{CF}$ lung disease.

\section{INTRODUCTION}

Previous studies have scrutinised the relationship of Bhalla or Brody CT scores observed in patients with cystic fibrosis (CF) to tests of ventilation heterogeneity such as the multiple breath washout (MBW). ${ }^{1-3}$ In advanced CF lung disease, the lung clearance index (LCI) is partly due to ventilation heterogeneities arising between lung units supplied by convective
In adult patients with cystic fibrosis (CF), the

flow, which can affect $30 \%-50 \%$ of total lung volume. ${ }^{4}$ This suggests that some structural correlate is expected to be visible on the resolution scale of CT. Bronchiectasis in the airways has the potential to impair convective gas flow into subtending airways. Our convection-dependent ventilation model of adult CF disease predicts an association between LCI and the number of lung units affected by bronchiectasis. $^{45}$ Thus, we tested the hypothesis that the number of bronchopulmonary segments with bronchiectasis detected on CT directly relates to LCI measured in the same patients with CF. We also examined data from a group of patients with non-CF bronchiectasis previously published by Bilton et al, ${ }^{6}$ to underline the specific role of bronchiectasis.

\section{METHODS}

Over a 1-year period, consecutive adult patients with stable CF visiting the outpatient clinic for their annual check-up were recruited (UZ Brussel ethical committee approval B143201213405). From 24 stable patients with non-CF bronchiectasis in Bilton et $a l^{6}$ who had both MBW and CT performed (across two sites), we retrieved raw data from 15 patients at the Sydney site and reanalysed these. In our prospective CF study group, lung function measurements (VmaxEncore; Cardinal Health, Ohio, USA) were followed by the nitrogen MBW test,
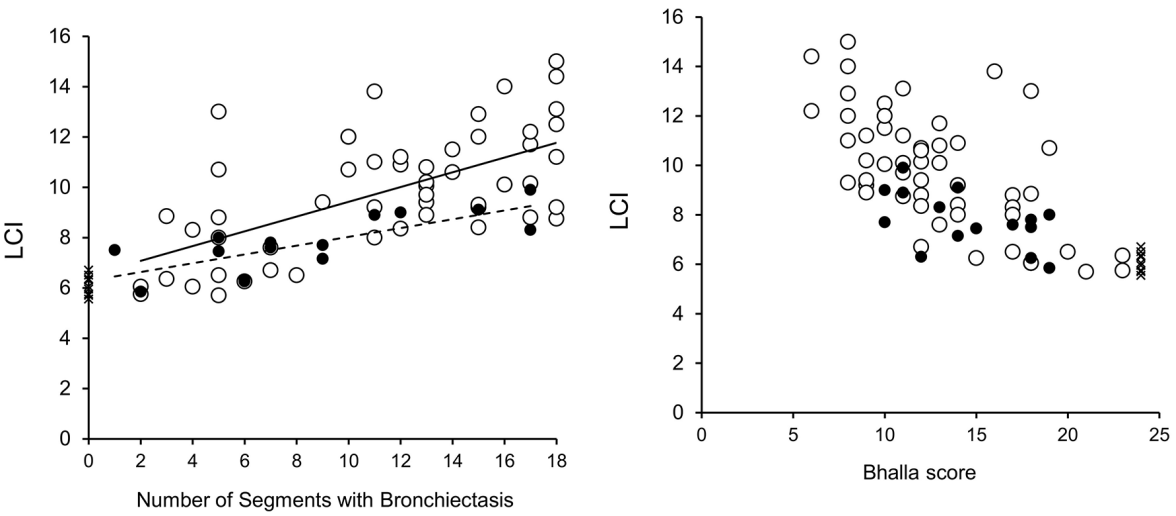

Figure 1 (A) LCl versus number of segments affected by bronchiectasis $\left(n_{B E}\right)$. Open circles: patients with CF with at least one bronchopulmonary segment affected by bronchiectasis $(n=54)$ and corresponding regression line (solid line; $r=+0.62$; simple regression slope: $0.3 \mathrm{LCl}$ increase per $\left.n_{B E}\right)$. Crosses: patients with CF without bronchiectasis $(n=9)$. Solid circles: patients with non-CF bronchiectasis $(n=15)$ and corresponding simple regression line (dashed line; $r=+0.76$; regression slope: $0.2 \mathrm{LCl}$ increase per $\mathrm{n}_{\mathrm{BE}}$ ). While the slope of the regression lines in the CF group (solid line) and in the non-CF group (dashed line) were not significantly different from each other (analysis of covariance; $p=0.26$ for 'heterogeneity of slopes'), their exact value may partly depend on patient group selection and corresponding $n_{B E}$ range. (B) $L C l$ versus Bhalla score. Open circles: patients with CF with at least one bronchopulmonary segment affected by bronchiectasis $(n=54)$. Crosses: patients with CF without bronchiectasis $(n=9)$. Solid circles: patients with nonCF bronchiectasis $(n=15)$. CF, cystic fibrosis; $L C l$, lung clearance index. performed in triplicate, and analysed as previously described. ${ }^{5}$ From mean expired concentration curves, we derived LCI and curvilinearity (curv), the latter being a more specific marker of convection-dependent ventilation heterogeneity. ${ }^{5}$ From phase III slopes, we computed indices of acinar and conductive ventilation heterogeneity, adapted for severe lung disease (Sacin*,Scond*). ${ }^{5}$ All measured parameters were related to reference values in age range 20-80 years.'

Volumetric CT images were obtained during quiet breathing, using MDCT (Discovery $750 \mathrm{HD}, \mathrm{GE}$ Healthcare; Milwaukee, Wisconsin, USA) with a slice thickness $0.625 \mathrm{~mm}$. Manual CT scoring included identification of pattern and severity of bronchiectasis, peribronchial thickening, mucus plugging, bullae, emphysema, collapse and consolidation. ${ }^{1}$ The sum of subscores was then subtracted from 25 (maximum value) to obtain the Bhalla score. For each patient, the number of segments affected by bronchiectasis $\left(\mathrm{n}_{\mathrm{BE}}\right)$ was recorded; bronchiectasis CT subscore 1, 2 and 3, respectively, correspond to $n_{B E}$ ranges $1-5,6-9$ and $>9$. $^{1}$

Statistical analyses were performed with MedCalc (V.16.4.3, Mariakerke, Belgium) accepting statistical significance at $\mathrm{p}=0.05$.

\section{RESULTS}

Figure 1A shows significant associations between LCI and $n_{B E}$ in the main study group (patients with $\mathrm{CF} ; \mathrm{n}=63$ ) and in the ancillary non-CF bronchiectasis group $(n=15)$ (table 1), consistent with predictions of an almost linear dependence of LCI on $\mathrm{n}_{\mathrm{BE}}$ for $\mathrm{n}_{\mathrm{BE}}>0$ (see online supplementary figure 1). Significant correlations between $n_{B E}$ and LCI, and also between $n_{B E}$ and curv (see online supplementary table 1 ), were maintained when only including patients with CF, with bronchiectasis subscore $>1$ (ie, $\mathrm{n}_{\mathrm{BE}}>5$ ).

To further explore the role of conductive ventilation heterogeneity we performed a stepwise multiple linear regression on $\mathrm{n}_{\mathrm{BE}}$, including both Sacin* and Scond* (which are both known to contribute to ventilation heterogeneity in $\mathrm{CF})$. When considering all patients with $\mathrm{CF}$ with at least one segment affected by bronchiectasis (open circles in figure 1A), both Sacin* and Scond* were retained in the model $\left(S_{\text {Sacin }}^{*}\right.$ : regression coefficient (SE): 6.2 (2.6); partial $r=0.32 ; \mathrm{p}=0.02$; Scond*: regression coefficient (SE): 41.1 (8.9); partial $r=0.54 ; \mathrm{p}<0.001$; adjusted $\left.R^{2}=0.42 ; \quad n=54\right)$. However, when including only patients with bronchiectasis 
Table 1 Baseline characteristics of the main study group (CF) and ancillary dataset (non-CF)

\begin{tabular}{|c|c|c|c|c|c|}
\hline & & \multicolumn{2}{|c|}{ Patients with CF $(n=63 ; 24 F)$} & \multicolumn{2}{|c|}{$\begin{array}{l}\text { Patients with non-CF } \\
\text { bronchiectasis }(n=15 ; 9 F)\end{array}$} \\
\hline & & Mean & $95 \% \mathrm{Cl}$ for the mean & Mean & $95 \% \mathrm{Cl}$ for the mean \\
\hline Age & (year) & 29 & (27 to 31 ) & 62 & (55 to 68 ) \\
\hline Height & $(\mathrm{cm})$ & 172 & (170 to 174 ) & 167 & (163 to 170$)$ \\
\hline BMI & $\left(\mathrm{kg} / \mathrm{m}^{2}\right)$ & 21 & (21 to 22 ) & 25 & (22 to 27 ) \\
\hline \multicolumn{6}{|l|}{ HRCT score } \\
\hline Bhalla score & & 14.4 & (13.0 to 15.8 ) & 14.6 & (12.7 to 16.5 ) \\
\hline \multicolumn{6}{|l|}{ Spirometry } \\
\hline \multirow[t]{2}{*}{$\mathrm{FEV}_{1}$} & (\%pred) & 66 & (61 to 71$)$ & 65 & (59 to 71 ) \\
\hline & (Z score) & -5.4 & $(-6.6$ to -4.2$)$ & -4.4 & $(-5.5$ to -3.4$)$ \\
\hline \multirow[t]{2}{*}{ FVC } & (\%pred) & 82 & (79 to 85 ) & 72 & (66 to 78 ) \\
\hline & (Z score) & -1.9 & $(-2.3$ to -1.5$)$ & -2.9 & $(-3.7$ to -2.2$)$ \\
\hline \multirow[t]{2}{*}{$\mathrm{FEV}_{1} / \mathrm{FVC}$} & $(\%)$ & 0.65 & (0.61 to 0.69 ) & 0.68 & ( 0.65 to 0.720 \\
\hline & (Z score) & -3.6 & $(-4.4$ to -2.8$)$ & -1.7 & $(-2.3$ to -1.1$)$ \\
\hline \multicolumn{6}{|l|}{ MBW } \\
\hline \multirow[t]{3}{*}{ LCl } & $(-)$ & 9.3 & (8.7 to 10.0 ) & 7.8 & (7.2 to 8.4 ) \\
\hline & (\%pred) & 152 & (142 to 163 ) & 115 & (106 to 123 ) \\
\hline & (Z score) & 5.0 & (4.1 to 5.8 ) & 1.6 & (0.5 to 2.6 ) \\
\hline \multirow[t]{3}{*}{ Curv } & $(-)$ & 0.50 & (0.45 to 0.55$)$ & 0.39 & (0.32 to 0.45$)$ \\
\hline & (\%pred) & 286 & (258 to 314 ) & 158 & (129 to 188$)$ \\
\hline & (Z score) & 4.6 & (3.9 to 5.3 ) & 1.7 & (0.9 to 2.5 ) \\
\hline \multirow[t]{3}{*}{ Sacin* } & $\left(L^{-1}\right)$ & 0.26 & ( 0.20 to 0.31$)$ & 0.34 & (0.25 to 0.44 ) \\
\hline & (\%pred) & 319 & (250 to 388 ) & 291 & (214 to 367 ) \\
\hline & (Z score) & 3.4 & (2.4 to 4.3 ) & 3.5 & (2.3 to 4.7 ) \\
\hline \multirow[t]{3}{*}{ Scond ${ }^{*}$} & $\left(L^{-1}\right)$ & 0.15 & (0.13 to 0.16 ) & 0.14 & (0.10 to 0.17 ) \\
\hline & (\%pred) & 416 & (364 to 467 ) & 271 & (211 to 332 ) \\
\hline & (Z score) & 6.4 & (5.4 to 7.3 ) & 2.6 & (1.8 to 3.3 ) \\
\hline
\end{tabular}

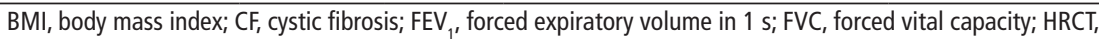
high-resolution computed tomography; LCl, lung clearance index; MBW, multiple breath washout.

CT subscore $>1(\mathrm{n}=42)$, only Scond* was retained (regression coefficient (SE): 30.6 (8.7); $r=0.49 ; \mathrm{p}=0.001)$.

The online supplementary file contains supportive data and study limitations.

\section{DISCUSSION}

We have established a highly significant relationship between the number of bronchial segments affected by bronchiectasis $\left(\mathrm{n}_{\mathrm{BE}}\right)$ and LCI in adult patients with CF, as predicted by a very simple mechanistic model showing a dependence of LCI on $n_{B E}$ which is almost linear for $n_{B E}>0$ (see online supplementary figure 1). The interpretation of this relationship was strengthened by the link between $\mathrm{n}_{\mathrm{BE}}$ and specific indices of convection-dependent ventilation heterogeneity (Scond* and curv) in our patient with CF group. In addition, the reanalysis of data from an ancillary group of patients with non-CF bronchiectasis confirmed the observed pattern of convective ventilation heterogeneity underlying the relationship between LCI and $n_{\mathrm{BE}}$.

In principle, LCI includes all ventilation heterogeneities down the lung periphery, including those in the acinar spaces. The predominant relationship of $\mathrm{n}_{\mathrm{BE}}$ with conductive ventilation heterogeneity (Scond*) over Sacin* indicates that ventilation heterogeneity associated with $n_{B E}$ occurs between relatively large lung units, at least large enough to be supplied by convective flow. If convective flow into a lung unit is hampered by the bronchiectatic airway supplying it, average ventilation of the corresponding bronchopulmonary segment will decrease. One large bronchiectatic airway or several more peripheral ones may lead to the same degree of underventilation of a bronchopulmonary segment. The degree of LCI increase with $\mathrm{n}_{\mathrm{BE}}$ (figure 1A) actually provides a semi-quantification of the extent of underventilation of the affected bronchopulmonary segments. Indeed, our experimental range of $0.2-0.3$ LCI increase per $\mathrm{n}_{\mathrm{BE}}$, corresponds to affected segments receiving only $40 \%$ of their normal ventilation. ${ }^{5}$ This should be measurable by combined lung imaging modalities, where airways responsible for local underventilation visualised by MRI can be identified by CT. ${ }^{8}$

Previous studies ${ }^{1-3}$ have shown correlations between LCI and CT scores in patient with CF groups ${ }^{9}$ but these also included patients with CF with normal LCI. Here, LCI correlates with Bhalla score even when excluding patients without bronchiectasis (figure 1B). Nevertheless, categorising $\mathrm{n}_{\mathrm{BE}}$ into corresponding scores blurs any potential correlation between LCI and CT features. Indeed, according to the $0.2-0.3$ LCI units increase per $n_{B E}$ obtained here (figure 1A), any two patients with either 10 or 18 bronchopulmonary segments affected by bronchiectasis could have an average LCI difference of $\sim 2$ units $(=0.25 *(18-10))$ despite having the same CT subscore of 3 .

In $\mathrm{CF}$, interventions such as physiotherapy or intravenous antibiotics have led to variable LCI effects, whereas other treatments have shown consistent LCI decreases (eg, ref 10). The LCI decreases following treatment with ivacaftor stabilised after a few weeks, but also showed a residual LCI abnormality. ${ }^{10}$ The clinical implication of our study is that the extent of bronchiectasis increases the lowest possible LCI value to which an individual patient can be reversed after treatment. Even if mucus can be partially displaced or evacuated by any given treatment, the extent of bronchiectasis is determinant of the LCI portion that cannot be reversed.

\section{Sylvia Verbanck, ${ }^{1}$ Gregory G King, ${ }^{2}$ Wenxiao Zhou, ${ }^{3}$ Anne Miller, ${ }^{3}$ Cindy Thamrin, ${ }^{2}$ Daniel Schuermans, ${ }^{1}$ Bart Ilsen, ${ }^{4}$ Caroline W Ernst, ${ }^{4}$ Johan de Mey, ${ }^{4}$ Walter Vincken, ${ }^{1}$ Eef Vanderhelst ${ }^{1}$}

${ }^{1}$ Respiratory Division, University Hospital UZBrussel, Vrije Universiteit Brussel, Brussel, Belgium ${ }^{2}$ Woolcock Institute of Medical Research, The University of Sydney, Sydney, New South Wales, Australia ${ }^{3}$ Department of Radiology and Nuclear Medicine, North Shore Hospital, Sydney, New South Wales, Australia ${ }^{4}$ Department of Radiology, University Hospital UZBrussel, Vrije Universiteit Brussel, Brussels, Belgium

Correspondence to Dr Sylvia Verbanck, Respiratory Division, University Hospital UZBrussel, Vrije Universiteit Brussel, Laarbeeklaan 101, Brussels 1090, Belgium; sylvia.verbanck@uzbrussel.be

Contributors SV and EV: designed the study and drafted the manuscript. DS, BI, CWE and JdM: performed data analysis at the Brussels site. GGK, WZ, AM and CT: performed data analysis at the Sydney site. SV, CT, GGK, WV and EV: supervised the study and reviewed the final manuscript version. 
Funding This project was supported by the Fund for Scientific Research-Flanders (FWO-Vlaanderen, Belgium).

Competing interests None declared.

Provenance and peer review Not commissioned; externally peer reviewed.

(c) Article author(s) (or their employer(s) unless otherwise stated in the text of the article) 2018. All rights reserved. No commercial use is permitted unless otherwise expressly granted.

- Additional material is published online only. To view please visit the journal online (http://dx.doi.org/ 10.1136/thoraxjnl-2017-210496).

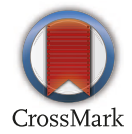

To cite Verbanck S, King GG, Zhou W, et al. Thorax 2018:73:82-84.

Received 8 May 2017

Revised 14 July 2017
Accepted 14 August 2017

Published Online First 2 September 2017

\section{SP Linked}

- http://dx.doi.org/10.1136/thoraxjnl-2017-210917

Thorax 2018;73:82-84.

doi:10.1136/thoraxjnl-2017-210496

\section{REFERENCES}

1 Ellemunter H, Fuchs SI, Unsinn KM, et al. Sensitivity of Lung Clearance Index and chest computed tomography in early CF lung disease. Respir Med 2010;104:1834-42

2 Gustafsson PM, De Jong PA, Tiddens HA, et al. Multiple-breath inert gas washout and spirometry versus structural lung disease in cystic fibrosis. Thorax 2008:63:129-34.

3 Owens CM, Aurora P, Stanojevic S, et al. London Cystic Fibrosis Collaboration. Lung Clearance Index and HRCT are complementary markers of lung abnormalities in young children with CF. Thorax 2011;66:481-8.

4 Verbanck S, Paiva M, Paeps E, et al. Lung clearance index in adult cystic fibrosis patients: the role of convection-dependent lung units. Eur Respir 2013:42:380-8

5 Verbanck S, Paiva M, Schuermans D, et al. Acinar and conductive ventilation heterogeneity in severe CF lung disease: back to the model. Respir Physiol Neurobiol 2013:188:124-32.

6 Bilton D, Daviskas E, Anderson SD, et al. Phase 3 randomized study of the efficacy and safety of inhaled dry powder mannitol for the symptomatic treatment of non-cystic fibrosis bronchiectasis. Chest 2013:144:215-25.

7 Verbanck S, Van Muylem A, Schuermans D, et al. Transfer factor, lung volumes, resistance and ventilation distribution in healthy adults. Eur Respir J 2016;47:166-76

8 McMahon CJ, Dodd JD, Hill C, et al. Hyperpolarized 3helium magnetic resonance ventilation imaging of the lung in cystic fibrosis: comparison with high resolution CT and spirometry. Eur Radiol 2006;16:2483-90.

9 Irving SJ, Ives A, Davies G, et al. Lung clearance index and high-resolution computed tomography scores in primary ciliary dyskinesia. Am J Respir Crit Care Med 2013;188:545-9.

10 Kane M, Gonska T, Jensen $\mathrm{R}$, et al. Lung clearance index response in patients with CF with class III CFTR mutations. Thorax 2016;71:476-7. 